International Journal of Molecular Medicine and Advance Sciences 4 (1): 1-7, 2010

ISSN: $1813-176 \mathrm{X}$

(C) Medwell Journals, 2010

\title{
A Histopathological Study of Severity of Cerebral Candidiasis as a Result of Immunosuppression Caused by Breast Carcinoma
}

\author{
${ }^{1}$ Srikumar Chakravarthi, ${ }^{3}$ Choo Zhen Wei, ${ }^{2} \mathrm{H}$.S. Nagaraja, ${ }^{1}$ Wong Shew Fung, \\ ${ }^{1}$ Mak Joon Wah and ${ }^{3}$ Shalini Sreekumar \\ ${ }^{1}$ Department of Pathology, ${ }^{2}$ Department of Human Biology, \\ Faculty of Medicine, International Medical University, Malaysia \\ ${ }^{3}$ Research Laboratory, Department of Post Graduate Studies, \\ International Medical University, Malaysia
}

\begin{abstract}
Candidiasis is a fungal infection which is prone to occur in people with immunosuppression due to debilitating diseases and nosocomial causes. While few studies have shown evidence of this disease co-existing with malignancy-induced immunosuppression disease, there never were any exclusive animal studies demonstrating this relationship, especially cerebral candidiasis with breast cancer. In fact, the exact causative mechanism of candidiasis is by and large still under much speculation. This study aims to demonstrate this relationship by observing the histopathological changes of the brain harvested from female $\mathrm{Balb} / \mathrm{c}$ mice which were experimentally induced with breast cancer and inoculated with Candida. The mice were randomly assigned to 5 different groups $(\mathrm{n}=12)$. The first group (Group 1) was injected with Phosphate Buffer Solution (PBS), the second group (Group 2) with Candida, third group (Group 3) with breast cancer and the final two groups, fourth and fifth group (Group 4 and 5) having co-existence of candidiasis and breast cancer at 2 different doses of candidiasis respectively. Inoculation of mice with candidiasis was done by intravenous injection of Candida albicans via the tail vein after successful culturing methods. Induction of mice with breast cancer is via injection of 4T1 cancer cells at the right axillary mammary fatpad after effective culturing methods. The prepared slides with the brains were stained with Haematoxylin and Eosin ( $\mathrm{H}$ and E), Periodic Acidic Schiff (PAS) and Gomori Methenamine Silver (GMS) stains for histopathology analysis. Grading of primary tumour and identification of metastatic deposits were done. Scoring of inflammation and congestion in the brains was done. Statistical tests done to compare group 2 and 4 showed that group 4 exhibited a highly statistically significant increase in inflammation and congestion ( $<<0.01$ ), especially in the cerebral areas. The median severity of candidiasis was also increased in group 4 as compared to group 2. In conclusion, based on the above evidences, cerebral candidiasis was significantly increased in mice with breast cancer.
\end{abstract}

Key words: Cerebral candidiasis, breast cancer, Candida albicans, immunosuppression, GMS, Malaysia

\section{INTRODUCTION}

Candidiasis is a disease caused by Candida sp. which are part of the normal flora found in the upper respiratory, gastrointestinal and female genital tract of the human body. Most cases of Candida infection result from Candida albicans, which is an opportunistic infection as it does not induce disease in immunocompetent individuals but can only do so in those with an impaired host immune defenses. Its infection is generally classified into superficial and deep.

It commonly infects the nails, skin and mucous membranes, especially the oropharynx, vagina, oesophagus and gastrointestinal tract. Occasionally, they invade the bloodstream and spread to other deep structure organs in the body such as kidneys, lungs, brain or other structures, causing systemic candidiasis (Levinson, 2006).

As of late, even though bloodstream infection has seen a decline in cases, yet the number of risk factors which could eventually lead to candidiasis has been increasing steadily (Richardson, 2005). The risk factors for candidiasis include immunosuppression due to chemotherapy or corticosteroid therapy, diabetes mellitus, low birth weight in neonates, broad spectrum antibiotics, long term catheterization, haemodialysis and parenteral nutrition. However it has mainly been observed that the

Corresponding Author: Srikumar Chakravarthi, Department of Pathology, Faculty of Medicine, International Medical University, 57000 Kuala Lumpur, Malaysia 
3 main group of patients associated with candidiasis are those with neutropenic cancer, organ or stem cell transplant patients and those undergoing intensive care procedures. Breast cancer is the most common cancer among Malaysian women. Approximately 1 in 20 women in the country develop breast cancer in their lifetime (Yip et al., 2006). There is a marked geographical difference in the worldwide incidence of breast cancer with a higher incidence in developed countries compared to developing countries. In a survey done in 2 prominent hospitals in Malaysia, the age incidence was similar and it was discovered that on average, half of the cases are delayed in presentation. This was possibly attributed to a strong belief in traditional medicine, the negative perception of the disease, poverty and poor education, coupled with fear and denial (Hisham and Yip, 2004).

While the exact mechanism leading to candidiasis is not known, the initiation and progression of candidiasis can be viewed as an imbalance in the host-pathogen relationship in favour of Candida albicans. Recent studies have shown that invasive candidiasis is a common and serious complication of cancer and its therapy (Di Nubile et al., 2005). In cancer patients, it has been hypothesized that it develops from initial gastrointestinal colonization with subsequent translocation into the bloodstream. It is unclear what components of the innate immune system are necessary for preventing Candida albicans dissemination from the GI tract, but it is hypothesized that both neutropenia and GI mucosal damage are critical for allowing widespread invasive Candida albicans disease (Koh et al., 2008).

Very few studies have documented the co-existence and plausible relationships between breast cancer and candidiasis (Gottfredsson et al., 2003; Ghoneum and Gollapudi, 2004; Anderson et al., 2000; Safdar et al., 2001). However, there have been no authentic studies on brain candidiasis and its relationship with breast cancer in experimentally induced mice. This study hopes to establish a hypothetical relationship between the most common cancer in women in Malaysia and brain candidiasis by using a mouse breast cancer model with Candida inoculation. Results from this study will provide a groundwork from which further studies such as immunology studies can be carried out to better understand the pathogenesis of Candida in cancer patients. It may also help bring better insight into the current treatment and pathophysiology of cancer which has itself been shown to be a risk factor to the predisposition of candidiasis.

\section{MATERIALS AND METHODS}

Experimental animals: Female Balb/c mice were used for the research, after prior approval from the Ethical committee. The mice were divided into 5 groups (Table 1). Dosing began when the mice were 10 weeks old and weighed between $15-25 \mathrm{~g}$. They were housed in groups of 6 mice for each metal cage located within the Animal Housing Facility in International Medical University. The mice were fed with standard mice chow and were given free access to water. The weight of the mice was recorded at the start, once every week thereafter and finally at the end of the experiment.

Culture of Candida yeast cells: The Candida yeast cells were obtained from patient clinical isolates (IMU research lab). Usage of sample was done with prior permission from the researcher. The cells were then subcultured onto a solid media of Sabouraud agar by streaking methods and stored in an incubator at $37^{\circ} \mathrm{C}$. Before harvesting the colonies for inoculation, one of the Candida colonies was subcultured into the YPD broth and left for $72 \mathrm{~h}$ in a shaking incubator (Certomat S11) fixed at $100 \mathrm{rpm}$ at a controlled temperature of $37^{\circ} \mathrm{C}$. After 3 days or on the stipulated day of inoculation, serum was added into the broth to allow for germ tubes formation to occur and left in the shaking incubator for an additional of $3 \mathrm{~h}$ with similar settings. The colonies were then harvested by means of centrifugation. The volume and concentration needed for inoculation was prepared by dilutions and calculated using a haemocytometer.

Inoculation of mice with candidiasis: The mice were first placed inside a retainer and a $27 \mathrm{G}$ needle syringe was used to inject $0.1 \mathrm{~mL}$ of Candida blastospores suspended in Phosphate Buffer Solution (PBS) with a concentration of $5 \times 10^{6}$ cells $\mathrm{mL}^{-1}$ via the tail vein made dilated by ethanol swap. This step was repeated with another group of mice with a concentration of $5 \times 10^{8}$ cells $\mathrm{mL}^{-1}$.

Table 1: Groups used in this research with their respective characteristics

\begin{tabular}{|c|c|c|c|}
\hline Group No. & Group description & Concentration per dose of $0.1 \mathrm{~mL}$ & Duration before dissection \\
\hline 1 & Control group (injected with PBS only) & - & 2 weeks \\
\hline 2 & Mice inoculated with Condida albicans & $5 \times 10^{6}$ cells $\mathrm{mL}^{-1}$ & 2 weeks \\
\hline 3 & Mice induced with breast cancer & $1 \times 10^{5}$ cells $\mathrm{mL}^{-1}$ & 4 weeks \\
\hline 4 & $\begin{array}{l}\text { Mice induced with breast cancer and subsequently } \\
\text { inoculated with Condida albicons }\end{array}$ & $\begin{array}{l}1 \times 10^{5} \text { cells } \mathrm{mL}^{-1} \text { of } 4 \mathrm{~T} 1 \text { breast cancer cells and } \\
5 \times 10^{6} \text { cells } \mathrm{mL}^{-1} \text { for } C \text { Candida albicans }\end{array}$ & 3 weeks +1 week \\
\hline 5 & $\begin{array}{l}\text { Mice induced with breast cancer and subsequently } \\
\text { inoculated with Condida albicons }\end{array}$ & $\begin{array}{l}1 \times 10^{5} \text { cells } \mathrm{mL}^{-1} \text { of } 4 \mathrm{~T} 1 \text { breast cancer cells and } \\
5 \times 10^{8} \text { cells mL } \mathrm{mL}^{-1} \text { for } C \text { condida albicans }\end{array}$ & 3 weeks +1 week \\
\hline
\end{tabular}


Culture of 4T1 breast cancer cells: The breast cancer cells (4Tl cell line, IMU research lab) were maintained and sub cultured into a $25 \mathrm{~cm}^{3}$ culture flask until they were healthy and had achieved a steady replicative rate. They were then harvested by means of centrifugation and kept suspended in the culturing medium. The volume and concentration needed for inoculation was prepared by dilutions and calculated using a haemocytometer.

Inducing mice with $4 \mathrm{~T} 1$ cancer cells: The mice were first anesthesized with diethyl ether before injection of $0.1 \mathrm{~mL}$ of $1 \times 10^{5}$ cells $\mathrm{mL}^{-1}$ was administered subcutaneously into the mammary fatpad at the axilla of the right arm.

Sample collection: The mice were weighed at the end of the experiment before being sacrificed with diethyl ether in a desiccator. The brains from all groups, primary breast tumours and spleens, livers, lungs, heart and kidneys were harvested. They were subsequently fixed in formalin $10 \%$ for at least 2 days.

Tissue processing: The fixed organs were then sectioned and processed to paraffin blocks. Sections of $4 \mu \mathrm{m}$ were taken on glass slides and were stained with Haematoxylin and Eosin (H and E), Periodic Acid Schiff (PAS) and Gomori Methenamine Silver (GMS) and were dehydrated, cleared and mounted with cover slips using DPX mountant media.

\section{RESULTS AND DISCUSSION}

The slides were observed under the light microscope for grading of the primary tumour, presence of metastatic deposits and extent of candidiasis in the brain by comparatively examining the slides stained in $\mathrm{H}$ and $\mathrm{E}$, PAS and GMS and extent of organ inflammation and congestion. Lastly, a correlation was made between the pathological lesions observed in the groups with that of the groups' mean gross weight changes.

The presence of candidiasis and histopathological scoring of inflammation and congestion changes in these brains was based on standard techniques used in previous studies (Fig. 1) (Lee et al., 2008; Black et al., 1999). Scoring of candidiasis (Balish, 2009) and grading of the primary tumour (Fig. 2) was done using the conventional method of analyzing the similarity of the cells to its tissue of origin as poorly differentiated, moderately differentiated and severely differentiated (Kumar et al., 2003).

Statistical analysis: In this study, 60 samples were studied and analyzed. All analytical data were expressed

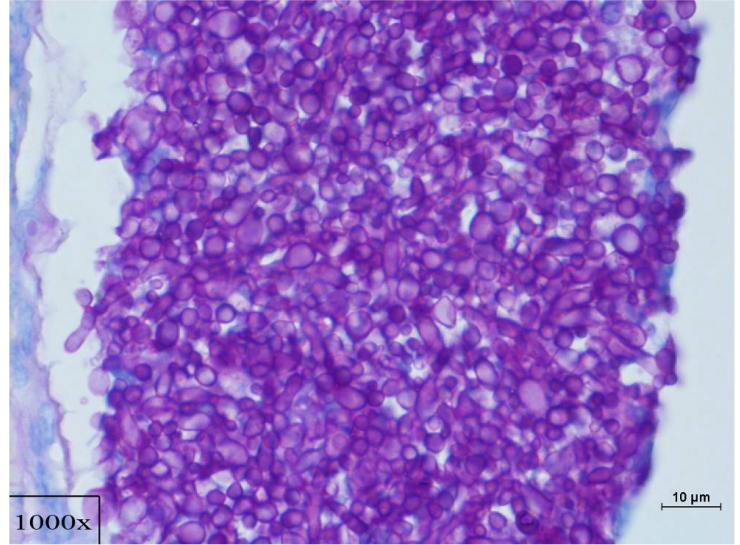

Fig. 1: Photomicrograph under oil immersion showing a colony of Candida yeast cells and hyphae in the cerebral cortex. The wall of Candida is stained magenta (1000x, PAS)

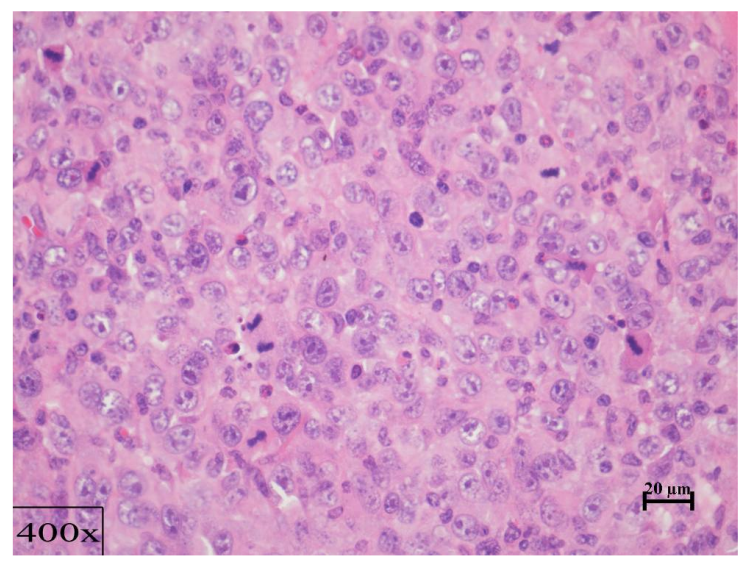

Fig. 2: Photomicrograph showing multiple mitotic figures and malignant cells in the primary breast tumour (400x, H and E)

in mean with standard deviation and with a 95\% confidence interval. The level of significance was set at 0.05 . Statistical tests that were used in the experiment were:

- Paired t-test for comparison of initial and final mean weight of mice in each group

- Kruskal-Wallis test for global comparison of groups for all the parameters

- Non-parametric Mann-Whitney-U test for comparison between 2 groups for each parameter

- Spearman's rho Test for correlation of candidiasis, cancer metastases, inflammation and congestion

The statistical tests were conducted with the aid of SPSS Statistical software version 16. For all the individual 
tests, $\mathrm{p}<0.05$ was taken and considered as significant. Paired t-test is a parametric method to test for any significant difference between the means on the same or related subject over time or in differing circumstances. From the test conducted, it was found that the $\mathrm{p}<0.05$ in all the groups with group 1,2 and 3 showing $p<0.01$. This means that there was a significant difference in the weight of the mice in all the groups at the initial and end of experiment (Table 2).

Based on the global comparison done for metastasis in each of the organs for all the groups, Mann-Whitney test for comparison between groups 3 and 4 showed a significant difference in all the organs except the brain $(\mathrm{p}<0.01)$ (Table 3). The kidneys showed a greater level of significance $(\mathrm{p}<0.01)$ as compared to the other organs. This shows that the presence of renal candidiasis as in group 4 has an effect on the extent of the metastatic growth in these organs.

By comparing the median severity of brain candidiasis between group 2 and 4 , it was observed that there was significant difference in its severity. In group 2 , the severity of candidiasis was mild while that in group 4 was moderate (Table 4) and more so in the cerebral hemispheres than deeper areas. These observations were also observed in slides stained in Periodic Acidic Schiff (PAS) and Gomori Methenamine Silver (GMS) stains.

Kruskal-Wallis test for global comparison between the groups for inflammation and congestion showed that there was a significant difference with $\mathrm{p}<0.01$ between these groups in all the brain (Table 5). Mann-Whitney test for comparison between group 2 and 4 for inflammation response showed a significant difference in all the brains. This shows that the co-existence of both candidiasis and cancer in the mice had a heightened effect on the severity of inflammation as compared to mice with candidiasis alone.

Mann-Whitney test for comparison between group 4 and 5 for extent of candidiasis showed that the increase in Candida dosage inoculated in group 5 with a concentration of $5 \times 10^{8}$ cells $\mathrm{mL}^{-1}$ compared to $5 \times 10^{6}$ cells $\mathrm{mL}^{-1}$ in group 4 exhibited statistical significant difference. This shows that the increased dose in group 5 showed a statistically significant effect on the inflammatory response seen in the brains. The correlation made between cerebral candidiasis and cancer metastases was significant.

Few studies have been done on experimental candidiasis in mice. This provided the research team the information on the necessary dosages and previous observations from which this experiment can draw comparison (De Repentigny, 2004; Wong et al., 2008; Ashman and Papadimitriou, 1987). Some of these
Table 2: Results of Paired t-test for gross weight of mice at initial and end of experiment

\begin{tabular}{lccc}
\hline Groups & $\begin{array}{c}\text { Mean initial } \\
\text { weight }(\mathrm{g})\end{array}$ & $\begin{array}{c}\text { Mean final } \\
\text { weight }(\mathrm{g})\end{array}$ & $\begin{array}{c}\text { Asymptote } \\
\text { significance }(\mathrm{p}<0.05)\end{array}$ \\
\hline 1 & 17.71 & 19.09 & $0.001^{* * *}$ \\
2 & 18.36 & 16.85 & $0.009^{* * *}$ \\
3 & 19.00 & 20.00 & $0.000^{* * *}$ \\
4 & 19.40 & 18.01 & $0.039^{*}$ \\
5 & 20.25 & 18.04 & $0.032^{*}$ \\
\hline
\end{tabular}

The mean gross weight in grams at initial and end was included; *Significant difference at $\mathrm{p}<0.05 ; * *$ Significant difference at $\mathrm{p}<0.01$

Table 3: Results of Kruskal-Wallis and Mann-Whitney test for comparison Asymptote significance $(\mathrm{p}<0.05)$

\begin{tabular}{lcc} 
Organs & $\begin{array}{c}\text { Kruskal-Wallis Test for } \\
\text { global comparison of organ } \\
\text { metastases among groups }\end{array}$ & $\begin{array}{c}\text { Mann-Whitney test for comparison } \\
\text { between group 3 and } 4 \text { for } \\
\text { extent of organ metastases }\end{array}$ \\
\hline Brain & 1.000 & - \\
Kidneys & $0.001^{* * *}$ & $0.001^{* *}$ \\
Lungs & $0.000^{* * *}$ & $0.016^{*}$ \\
Liver & $0.001^{* * *}$ & $0.015^{*}$ \\
Spleen & $0.001^{* * *}$ & $0.016^{*}$ \\
\hline *Significant difference at $\mathrm{p}<0.05 ; * *$ Significant difference at $\mathrm{p}<0.01$
\end{tabular}

Table 4: Histopathological scoring of brain Candidiasis in $\mathrm{H}$ and $\mathrm{E}$

\begin{tabular}{lc} 
Experimental groups & $\begin{array}{c}\text { Median of severity } \\
\text { of brain Candidiasis }\end{array}$ \\
$\begin{array}{l}\text { Group 2-Mice with Candida } \\
\left(5 \times 10^{6} \text { cells } \mathrm{mL}^{-1}\right)\end{array}$ & + \\
$\begin{array}{l}\text { Group 4-Mice with breast cancer }+ \\
\text { Candida }\left(5 \times 10^{6} \text { cells } \mathrm{mL}^{-1}\right)\end{array}$ & +++ \\
\hline Absent $(-)$; Mild $(+) ;$ Moderate $(++)$ and Severe $(++)^{+}$
\end{tabular}

Absent (-); Mild (+); Moderate (+) and Severe (++)

Table 5: Results of Kruskal-Wallis for global comparison between groups and Mann-Whitney Test for comparison

\begin{tabular}{lcc}
\hline & Asymptote significance $(\mathrm{p}<0.05)$ \\
\hline Liver & $\begin{array}{l}\text { Kruskal-Wallis test } \\
\text { of global comparison }\end{array}$ & $\begin{array}{c}\text { Mann-Whitney } \\
\text { test for comparison } \\
\text { between group 2 and } 4\end{array}$ \\
\hline Inflammation & $0.000^{* * *}$ & $0.001^{* *}$ \\
Congestion & $0.001^{* * *}$ & $0.005^{* *}$ \\
Candidiasis & $0.000^{* * *}$ & $0.000^{* * *}$ \\
Cancer metastasis & $0.001^{* *}$ & $0.001^{* *}$ \\
\hline *Significant difference at $\mathrm{p}<0.05 ; * *$ Significant difference at $\mathrm{p}<0.01$
\end{tabular}

studies have been dedicated to the observations of the correlation between candidiasis and other forms of immunosuppression such as chemotherapy, steroid therapy, antibiotic therapy and some other form of malignancies such as leukemia and oesophageal cancer.

However, there has never been an exclusive study on brain candidiasis and its relationship with breast cancer even though few epidemiological studies have shown a co-existence of breast cancer and systemic candidiasis in humans (Gottfredsson et al., 2003; Safdar et al., 2001; Talarmin et al., 2009). Hence, this study aims to focus on the relationship between renal candidiasis and breast cancer by comparing the behaviour of candidiasis when the body is subjected to a chronic disease state. This study was done, bearing in mind that breast cancer was not only chosen as an ideal representation of a 
chronic illness but also one that is capable of suppressing the host immune system (Mandeville et al., 1982; Semiglazov et al., 1978; Ortiz and Stoliar, 1988; Das et al., 1985).

This study is a pioneer research on the growth of renal candidiasis after inducing mice with breast cancer to study how the presence of a chronic illness such as breast cancer can by itself, be attributed to the increased severity of candidiasis. Scoring was done on the severity of candidiasis and grading of the primary tumour as well as identification of their metastatic deposits was conducted. Other parameters taken into consideration included gross weight of the mice at the beginning and end of experiment, inflammation and congestion in the brain, which was studied by scoring on a semiquantitative scale using an established technique as mentioned earlier.

Brain candidiasis: In group 2, the mice were solely inoculated with candidiasis by intravenous injection via the tail vein for a duration of 2 weeks. During the course of the experiment, signs of the disease can be appreciated in these mice. Their eye balls were protruded, their fur was roughened and they were generally less active as compared to the normal group with increased group huddle and sleep. They also appear very weak and thin with the curvatures of the bony structures beneath the mice visible to the naked eye. In addition, the weight taken at the start and end of the experiment showed that there was a statistically significant reduction in their mean weight. This could be attributed to the possible loss of appetite and general cachexic state of the mice.

Histopathologically, good growth of Candida colonies in the form of hyphae, yeast cells and pseudohyphae were discovered in the cerebral hemispheres, hippocampus and internal capsule. This was attributed to the mild dose of $5 \times 10^{6}$ cells $\mathrm{mL}^{-1}$ Candida cells injected and the short duration of the experiment as also shown in few other works.

Breast cancer study: In group 3 , the mice were injected at the mammary fatpad with $4 \mathrm{~T} 1$ cancer cells in the right axilla region with a concentration of $1 \times 10^{6} \mathrm{cells} \mathrm{mL}^{-1}$ (Pulaski and Rosenberg, 2001). After 4 weeks of growth and metastases, the mice were sacrificed for analysis. During the course of experiment, the weights of the mice were reduced for the first week before gradually increasing in the $3 \mathrm{rd}$ week. The growth of the primary tumour was detected as a palpable mass as early as the 10 th day and latest by the 14 th day. The mice were generally active for the first 2 weeks with no apparent deviations from that usually seen in the normal control group. However, by the 3rd week, they began to exhibit signs of lethargy and did not move quite as often and the mass of tumour began to appear significantly enlarged to the naked eye by the middle of 3rd week. Their general appetite was good. No distinct changes to the fur, eyes or prominent curvatures of the bony structures could be appreciated.

Grading done for the primary tumour showed it to be moderate to poorly differentiated with the majority presenting as poorly differentiated. Metastatic deposits were discovered in the lungs, liver and spleen with varying frequencies among the mice. Scoring for inflammation done showed that the median of severity of the entire group was moderate in the kidneys. The microabscesses that were observable in group 2 , were not seen in this group. Therefore, in this group with mice having breast cancer, the severity of inflammation and congestion seen in the kidney are mostly mild in severity with metastatic deposits found in the lungs, liver and spleen.

Correlation between brain Candidiasis and breast cancer: In group 4, the mice were first induced with breast cancer for 3 weeks and subsequently inoculated with Candida with a concentration of $5 \times 10^{6}$ cells $\mathrm{mL}^{-1}$ for 1 week. The time of induction with breast cancer was set at 3 weeks based on studies demonstrating that by this period, adequate metastases have occurred in all these organs (Tao et al., 2008). The initial stages of tumour growth and changes in the mice were similar as to that seen in group 3 but subsequently when Candida was injected, changes seen in group 2 were exhibited within days instead of the 2 nd week as seen in group 2. These changes include protruded eyes, roughened fur and they were generally inactive with increased huddle and sleep. Also, in the final stages of the experiment, a surge in the growth of tumour size could be observed.

Grading carried out for the primary tumour exhibited poorly differentiated tissue with atypical cells and high number of mitotic figures. Metastatic deposits were also discovered in the lungs, liver, spleen and even in the kidneys at a higher frequency as compared to that seen in group 3. These differences were statistically significant $(p<0.05)$. This shows that there was an increased frequency of metastatic deposits in these organs in group 4 as compared to that in group 3 . This suggests a possible role of Candida causing immunosuppression which by itself attributed to the increased metastatic deposits of the cancer seen in these organs. It also explains the late surge in tumour growth seen late in the experiment.

Notable changes in the brain include candidiasis involvement in the cerebral hemispheres, hippocampus and internal capsule. 
Scoring of inflammation showed moderate severity seen in the brain, as compared to just mild seen in group 2. Comparison of inflammation severity between these 2 groups was statistically significant $(\mathrm{p}<0.01)$.

As for congestion, this group exhibited moderate congestion in the brain as compared to mild in group 2 and while congestion was not seen in group 2 , this group showed mild congestion. Comparison between group 2 and 4 for congestion were statistically significant $(p<0.05)$. In conclusion, the severity of candidiasis, inflammation and congestion were seen at greater levels in breast cancer induced mice with candidiasis as compared to mice with only candidiasis.

Dose dependent study: In group 5, the mice were first induced with breast cancer and subsequently with candidiasis at a higher dose of $5 \times 10^{8}$ cells $\mathrm{mL}^{-1}$. They were similar to group 3 at the initial stages of the cancer growth but subsequently when candidiasis was injected, the mice died within the first week of inoculation at varied timings compared to group 4 where the time of inoculation with candidiasis was 1 week and mice living till the end of experiment. The sudden immediate death could be attributed to septicaemia.

Grading done on the primary tumour showed them all to be poorly differentiated. Metastatic deposits were found in the kidneys, lungs liver and spleen. Scoring of candidiasis done showed moderate to intense severity, which was highly significant. This means that with an increased dose, the brains exhibited candidiasis with increased levels of severity. Perhaps with a higher dose, the higher reaches of the body are much better accessible as the proportion eliminated by the liver or spleen is less.

In the scoring for inflammation, the brains showed a statistical significant difference when compared to group 4. The inflammation is much less in severity compared to that in group 4 which could be attributed to the short period of inoculation time before the demise of the mice resulting in inadequate time for chronic inflammation to take place.

In the scoring for congestion, group 5 showed significant severe congestion in the brains and this could be attributed to the acute changes seen in host response to a foreign pathogen.

Correlation of brain Candidiasis, cancer metastases, inflammation and congestion: The significant correlation between brain candidiasis and cancer metastases indicates that an increase in cancer metastatic deposits was accompanied by an increase in candidiasis severity. The statistically significant correlation of renal candidiasis with inflammation and congestion shows that increased levels of candidiasis is accompanied by increased levels of inflammation and congestion in the respective organs studied.

\section{CONCLUSION}

In this study, the mouse model of inducing breast cancer was successful and the method and the technique of inducing renal candidiasis was effective. Both these were also attributed to the efficient culturing methods. Also, growth of breast cancer and brain candidiasis, especially in the cerebrum, were observable in all the relevant groups. The weight of the mice was also correlated with the pathology suffered by the mice. All the objectives were carried out with precision and successfully achieved. Analysis was done based on the scoring of renal candidiasis, grading of metastatic deposits, inflammation and congestion in all the groups. The inflammation and congestion parameters showed a statistically significant increase in severity in brain when comparing the group of mice with brain candidiasis and breast cancer to the group of mice with brain candidiasis alone. The median severity of the entire group for candidiasis scoring in the brain was also increased for the group of mice with cerebral candidiasis and breast cancer. Hence, based on these evidences, cerebral candidiasis appears more severe in experimentally induced mice with breast cancer than in mice without.

\section{ACKNOWLEDGEMENTS}

This research was funded by research grant no. BMS I-02/2008 (12) from the International Medical University, Kuala Lumpur, Malaysia. We acknowledge the services of Dr. Thani PM and Dr. Annie Tay for their histopathological advise, Dr. Wong Shew Fung for her instructions on Candida culture, Prof. Ammu Radhakrishnan for her advise and valuable help in culturing breast cancer cell lines.

\section{REFERENCES}

Anderson, L.M., S. Krotz, S.A. Weitzman and B. Thimmapaya, 2000. Breast cancer-specific expression of the Candida albicans cytosine deaminase gene using a Cancer Gene. Ther., 7: 845-852.

Ashman, R.B. and J.M. Papadimitriou, 1987. Murine candidiasis. Pathogenesis and host responses in genetically distinct inbred mice. Immunol. Cell Biol., 65: 163-171. 
Balish, E.A., 2009. URA3 null mutant of Candida albicans (CAI-4) causes oro- esophageal and gastric candidiasis and is lethal for gnotobiotic, transgenic mice (Tgepsilon26) that are deficient in both natural killer and T cells. J. Med. Microbiol., 58: 290-295.

Black, C.A., F.M. Eyers, A. Russell, M.L. Dunkley, R.L. Clancy and K.W. Beagley, 1999. Increased severity of Candida vaginitis in $\mathrm{BALB} / \mathrm{c} \mathrm{nu} / \mathrm{nu}$ mice versus the parent strain is not abrogated by adoptive transfer of $\mathrm{T}$ cell enriched lymphocytes. J. Reprod. Immunol., 45: 1-18.

Das, S.N., N.N. Khanna and S. Khanna, 1985. A multiparametric observation of immune competence in breast cancer and its correlation with tumour load and prognosis. Ann. Acad. Med. Singapore, 14: $374-381$.

De Repentigny, L., 2004. Animal models in the analysis of Candida host-pathogen Curr. Opin. Microbiol., 7: 324-329.

Di Nubile, M.J., D. Hille, C.A. Sable and N.A. Kartsonis, 2005. Invasive candidiasis in cancer patients: Observations from a randomized clinical trial. J. Infect., 50: 443-449.

Ghoneum, M. and S. Gollapudi, 2004. Phagocytosis of Candida albicans by Cancer Detect Prev., 28: 17-26.

Gottfredsson, M., J.J. Vredenburgh, J. Xu, W.A. Schell and J.R. Perfect, 2003. Candidemia in women with breast carcinoma treated with high-dose. Cancer, 98: 24-30.

Hisham, A.N. and C.H. Yip, 2004. Overview of breast cancer in Malaysian women: A Asian J. Surg., 27: $130-133$.

Koh, A.Y., J.R. Kohler, K.T. Coggshall, N. van Rooijen and G.B. Pier, 2008. Mucosal damage and neutropenia are required for Candida albicans dissemination. PLoS Pathogens, 4: 35-35.

Kumar, V., R.S. Cotran and S.L. Robbins, 2003. Robbins Basic Pathology. 7th Edn., WB Saunders Co., UK., ISBN: 1416025340, pp: 436-438.

Lee, K.H., Y.S. Chen, J.P. Judson, S. Chakravarthi, Y.M. Sim and H.M. Er, 2008. The effect of water extracts of Euphorbia hirta on cartilage degeneration in arthritic rats. Malays J. Pathol., 30: 95-102.
Levinson, W., 2006. Review of Medical Microbiology and Immunology 9th Edn., McGraw-Hill Co., New York, ISBN: 0-07-110438-0, pp: 134-136.

Mandeville, R., G. Lamoureux, S.L. Poisson and R. Poisson, 1982. Biological markers and breast cancer. A multiparametric study. II. Depressed immune competence. Cancer, 50: 1280-1288.

Ortiz, O.C. and A. Stoliar, 1988. Immunological changes in human breast cancer. Eur. J. Gynaecol. Oncol., 9: 502-514.

Pulaski, B.A. and S.O. Rosenberg, 2001. Mouse 4T1 breast tumor model. Curr. Protoc. Immunol., 5: 202-211.

Richardson, M.D., 2005. Changing patterns and trends in systemic fungal. J. Antimicrob. Chemother., 56: i5-i11.

Safdar, A., V. Chaturvedi, E.W. Cross, S. Park, E.M. Bernard and D. Armstrong, 2001. Prospective study of Candida species in patients at a comprehensive cancer center. Antimicrob. Agents Chemother, 45: 2129-2133.

Semiglazov, V.F., V.B. Kondrat'ev, A.I. Mar'enko, E.G. L'Vovich and B.N. Sofronov, 1978. Immunologic reactivity of breast cancer patients. Vopr. Onkol., 24: 74-79.

Talarmin, J.P., D. Boutoille, P. Tattevin, S. Dargere, P. Weinbreck and S. Ansart et al, 2009. Epidemiology of candidemia: A one-year prospective observational study in the west of France. Med. Mal. Infect., 4: 122-127.

Tao, K., M. Fang, J. Alroy and G.G. Sahagian, 2008. Imagable 4T1 model for the study of late stage breast cancer. BMC Cancer, 8: 228-231.

Wong, S.F., J.W. Mak and C.K. Pook, 2008. Potential use of a monoclonal antibody for the detection of Candida antigens in an experimental systemic candidias is model. Hybridoma (Larchmt), 27: 361-373.

Yip, C.H., N.A. Taib and I. Mohamed, 2006. Epidemiology of breast cancer in Malaysia. Asian Pac. J. Cancer Prev., 7: 369-374. 